\title{
Notícias de Eventos e Livros
}

\author{
News of Events and Books
}

\section{Eventos}

$2^{\circ}$ Semestre de 2013

\section{Semana de História - 23 a 25 de Outubro}

\begin{abstract}
A XIV Semana de História teve como tema principal "Teorias e Práticas do Fazer Histórico"com o objetivo de contribuir para a disseminação e a troca de reflexões em pesquisas sobre recentes tendências historiográficas, teóricas e metodológicas da área, principalmente dentro das linhas

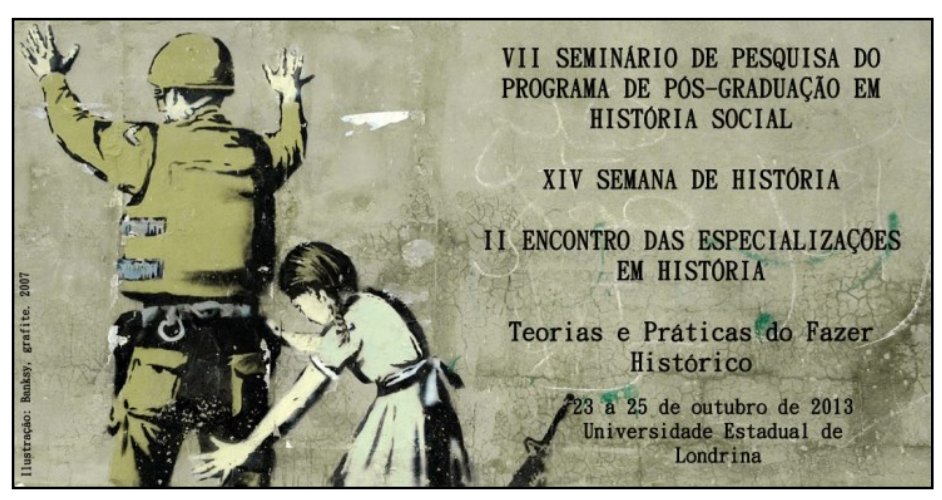
de pesquisa do departamento: "Territórios do Político", "Cultura, Representações e Religiosidades", e "História e Ensino". Integrando os três níveis de formação profissional de História da Universidade Estadual de Londrina - a graduação, a pós-graduação lato sensu e a pós-graduação strictu senso - a XIV Semana de História dividiu-se em dois eventos específicos: o VII Seminário de Pesquisa do Programa de Pós-Graduação em História Social, e o II Encontro das Especializações em História da UEL.
\end{abstract}




\section{Seminário de Pesquisa do Programa de Pós-Graduação em História Social; II Encontro das Especializações em História - 23 a 25 de Outubro}

Envolvendo os próprios estudantes e alunos de outras instituições de ensino superior do Paraná e demais regiões do país, os eventos contaram com Conferências, WebConferência, Mesas-Redondas e Sessões de Comunicação pensadas a partir das linhas temáticas do Programa de Pós-Graduação em História Social: Territórios do Político, História e Linguagens, História e Ensino, e Práticas Culturais, Memória e Imagem. Foram apresentados 99 trabalhos nas comunicações, divididos por linha temática e nível de formação, somados a 12 participantes de 4 mesas-redondas e 3 conferencistas. Demais informações podem ser encontradas no portal do evento, bem como os Anais com os trabalhos completos a serem publicados em breve: http://www.uel.br/pos/mesthis/XIVSemanaHistoria/index.htm

\section{Livros}

$2^{\circ}$ Semestre de 2013

\section{OLINTO, Beatriz Anselmo; SOCHODOLAK, Hélio; ARIAS NETO, José Miguel (org). A escrita da história: Fragmentos de historiografia contemporânea. Ponta Grossa: ANPUH-} $P R, 2013$.

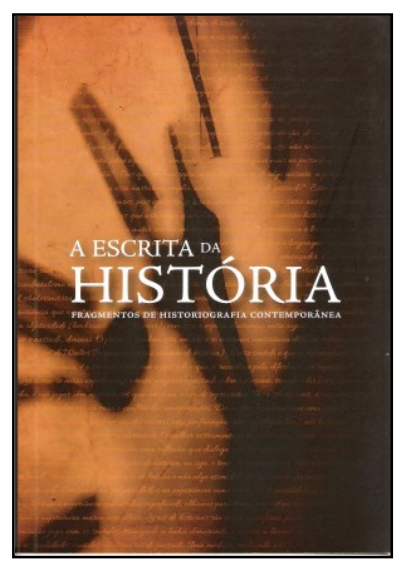

O livro "A escrita da História"leva o nome do tema principal do XIII Encontro Regional de História, sediado pela Universidade Estadual de Londrina em Outubro de 2012. Os textos foram selecionados pelos coordenadores de Simpósios Temáticos e aprovados pelos organizadores do livro e corroboram com o subtítulo "Fragmentos de Historiografia Contemporânea" ao apresentar para o leitor os caminhos que têm sido percorridos por historiadores paranaenses em suas pesquisas. O livro, financiado pela Fundação Araucária e Associação Nacional de História (ANPUH-PR), também conta com um artigo do conferencista convidado Franklin R. Ankersmit, autor do livro A Escrita da História: a Natureza da Representação Histórica, lançado durante o evento. (Resumo com base na apresentação do livro) 


\section{SOCHODOLAK, Hélio; ARIAS NETO, José Miguel (org). Ensaios de História Política e Cultural. Guarapuava: Editora da Unicentro, 2013.}

"Para uma história política plural e voltada para as práticas cotidianas formais e não-formais. A história política ao microscópio, vinculada à memória dos lugares, da infância, dos prazeres, da cultura definida num sentido mais amplo." "Cultura" e"política", enquanto objetos de relfexão histórica, sofreram transformações e ampliações teóricas e metodológicas ao longo do século $\mathrm{XX}$, chegando, ao final deste, como instrumentos através dos quais podemos compreender melhor o "ser" humano em toda a sua complexidade. O livro, uma coletânea de ensaios de pesquisadores interligados, ilustra e se insere nos movimentos de renovação da historiografia, que introduzem novos problemas,

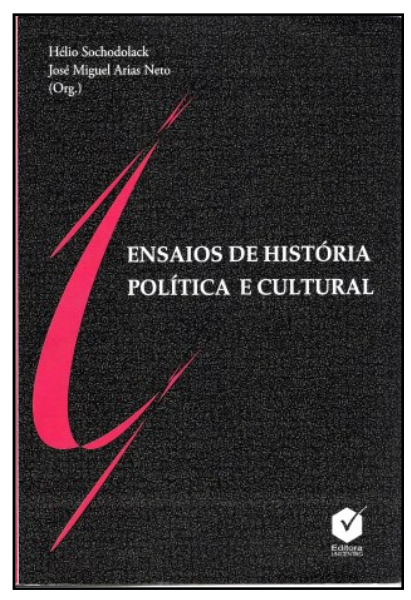
objetos e fontes ao mesmo tempo que resgata e coloca sob nova perspectiva aqueles condenados pelo historicismo. Com pesquisas e temáticas desafiadoras, que vão desde aproximações entre Foucalt e Nietzsche, até o cotidiano do ensino em sala de aula, passando pelo teatro, escravidão e tráfico negreiro no Brasil oitocentista, entre outras, os artigos carregam multiplicidade teórica, metodológica e disciplinar cujo objetivo principal é transmitir-se ao público local ao mesmo tempo em que refletem preocupações contemporâneas de âmbito nacional sobre os campos da cultura e da política. (Resumo com base no prefácio do livro)

$1^{\circ}$ Semestre de 2013

DURAN, Maria Renata da Cruz. Retórica à moda brasileira: Transições da cultura oral para a cultura escrita no ensino fluminense de 1746 a 1834. São Paulo: Editora UNESP, 2013.

Fruto de tese de doutorado defendida em 2009 na UNESP/Franca, Retórica à moda brasileira é uma versão mais coesa, polida e atual de um trabalho de pesquisa sobre a importância da retórica e da eloquência na educação do Rio de Janeiro dos séculos XVIII e XIX. Os limites desse estudo são os anos de 1759, quando a reforma no ensino lusitano deu novo fôlego à disciplina de retórica, uma vez que a colocou no lugar do latim

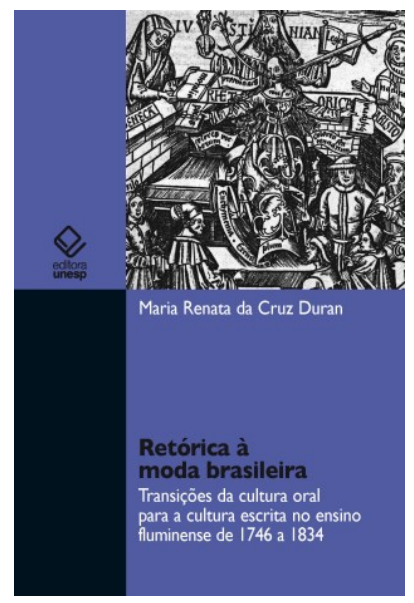


como matéria que dava acesso à universidade, e, 1834, quando as Lições elementares de eloquência nacional para uso da mocidade de ambos os hemisférios, de Francisco Freire de Carvalho foram adotadas como referência para a disciplina em todo o território brasileiro, uniformizando seu ensino. No livro, 4 capítulos foram dispostos a fim de dar a conhecer essa trajetória da retórica em solo nacional: Revolução e instrução, em que documentos oficiais foram utilizados para análise da política de Estado que promoveu essa mudança; Mestres e pupilos, em que os personagens envolvidos nessa trama educacional receberam maior atenção; Compêndios e manuais, aonde os materiais de ensino disseminados na época, bem como seus usos foram trabalhados; e, por fim, Jornalistas e leitores, quando procurei avaliar, por meio dos jornais literários da época, qual o alcance da disciplina nos modos de produção textual do início do oitocentos. Entre outras razões, um das principais justificativas para a redação desse trabalho era apresentar, de maneira inédita, como, nas origens de uma história da educação nacional, se forjaram a invenção e difusão de um discurso de nação brasileira. Foi, pois, no escrutínio da prevalência da oralidade, haja vista tudo o que ela representa, no perfil da atuação intelectual brasileira que nos fixamos para atingir tal objetivo. (Resumo fornecido pela autora)

\section{RAMOS, Márcia Elisa Teté(org). Estágio/Pesquisa: Ideias históricas de alunos do Ensino Médio. São Paulo: Clube de Autores, 2013.}

Este livro consiste em uma das atividades do Laboratório de Ensino de História da Universidade Estadual de Londrina, na articulação com as disciplinas ligadas ao estágio do curso de história ministradas pela $\operatorname{Prof}^{\mathrm{a}} \operatorname{Dr}^{\mathrm{a}}$ Márcia Elisa Teté Ramos. Graduandos do $4^{\circ}$ ano matutino do curso de história da UEL, por intermédio de um instrumento de pesquisa e pela observação participante, coletaram elementos sobre o universo cultural de alunos do Ensino Médio do Colégio de Aplicação de Londrina, bem como sobre suas noções sobre a história e seu ensino. As noções destes sujeitos foram analisadas conforme referenciais próprios do campo investigativo da história e serviu ao propósito de

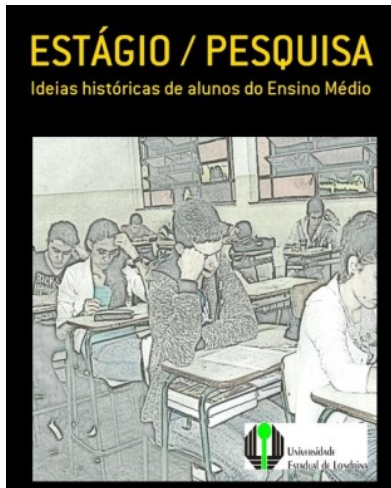

Márcia Elisa Teté Ramos [Org.] fundamentar posteriormente as ações de estágio. Portanto, buscou-se uma relação entre pesquisa e ensino, considerando que o profissional da história é tanto o historiador como o professor de história. O livro pode ser adquirido na forma de E-book ou impresso sob encomenda no site da editora: <www.clubedeautores.com.br> (Resumo fornecido pela organizadora) 
$1^{\circ}$ Semestre de 2012

SOARES, Marco Antonio Neves. Da Alemanha aos trópicos: identidades judaicas na terra vermelha (1933-2003). Londrina: EDUEL, 2012.

O livro leva o leitor numa viagem da República de Weimar até a fundação da Colônia Gleba Roland e da cidade de Rolândia, no Paraná, lugares que se tornaram refúgios para perseguidos do regime nacional-socialista. $\mathrm{O}$ contexto e o processo de transformação do "alemão" em "judeu"pelas Leis de Nuremberg, suas estratégias de sobrevivência na Alemanha nazista, e as estratégias de emigração para o Brasil (através da triangulação comercial que envolvia alemães, ingleses e os agentes da Companhia de Terras Norte do Paraná no Brasil) são cuidadosamente examinados. Também tem foco o processo de reconstrução da vida desses refugiados, que, de forma complexa e

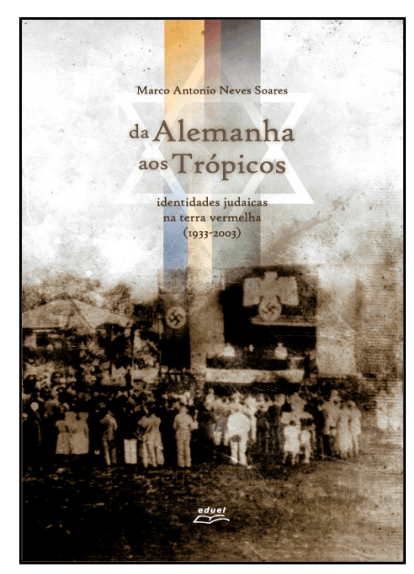
imbricada, envolve a chegada à Rolândia, a contrução das comunidades, as associações e os conflitos entre os migrantes, e a reelaboração das suas identidades, que se faz entre a experiencia do exílio e a edificação da "nova casa". Dessa forma, através de fontes documentais como memórias escritas e orais e vestígios de cultura material, investiga-se neste livro as circusntancias desse refúgio buscando compreender as teias de relações estabelecidas pelos refugiados entre a Alemanha, o Brasil e o judaísmo. (Resumo com base na apresentação do livro) 